\title{
Reducing post-harvest food losses through innovative collaboration: Insights from the Colombian and Mexican avocado supply chains
}

\author{
Carolina Arias Bustos, Ellen H.M. Moors* \\ Copernicus Institute of Sustainable Development, Utrecht University, Princetonlaan 8a, 3584 CB Utrecht, The Netherlands
}

\section{A R T I C L E I N F O}

\section{Article history:}

Received 31 October 2017

Received in revised form

8 June 2018

Accepted 16 June 2018

Available online 21 June 2018

\section{Keywords:}

Innovative collaboration

Postharvest losses

Sustainable food supply chains

Avocado

\begin{abstract}
A B S T R A C T
Postharvest losses along food supply chains have far reaching consequences for the environment and affect the social and economic conditions of food supply chain participants, especially of those in developing countries. This paper explores the structural inefficiencies that lead to postharvest losses and analyses how innovative collaboration could lead to more sustainable food supply chains (FSCs) by reducing those inefficiencies. Innovative collaboration is defined as the improvement or creation of interorganizational relationships through which FSC participants can exchange information, align incentives, engage in effective partnerships and improve their use of technology. This research distinguishes two research questions: First, how do FSC participants interact and which structural inefficiencies leading to postharvest losses can be identified in global food supply chains? And second, what are the main drivers and barriers of FSC participants to engage in innovative collaboration to reduce postharvest losses within global food supply chains? Two case studies explore the supply chain of avocados, especially due to their high susceptibility to postharvest losses, and focus on avocados from Mexico and Colombia imported into the Netherlands. Data was collected through semi-structured interviews with avocado importers, producers/exporters, packers and growers' associations, governmental organizations, and knowledge institutions. Informal interviews were held with producers and suppliers of other agricultural products traded globally. Using the software NVIVO, the collected data from interviews, documents and literature was structured allowing patterns and categories in the data to be discerned. The contribution of this paper is a typology of structural inefficiencies in global food supply chains, which provides insight into the social drivers of postharvest losses. Three categories of structural inefficiencies leading (directly or indirectly) to postharvest losses were identified: (1) corporate inefficiencies, (2) cognitive and affective inefficiencies, and (3) tangible inefficiencies. Effective partnerships were found to be the backbone of innovative collaboration, and the largest contributor to the reduction of postharvest losses, functioning as catalysts of trust, communication, cooperation and innovation, in addition to contributing to reduce structural inefficiencies along food supply chains.
\end{abstract}

(C) 2018 Elsevier Ltd. All rights reserved.

\section{Introduction}

Currently, one third to half of all food globally produced is lost or wasted along food supply chains (FSCs) (Lundqvist et al., 2008; Kummu et al., 2012; FAO, 2013). Arguably, any production endeavor in which half of the production is wasted or lost due to an inefficient allocation of natural and social resources can be considered unsustainable and a market failure (Daly and Farley, 2011). This waste and loss of food has far reaching consequences

\footnotetext{
* Corresponding author.

E-mail address: e.h.m.moors@uu.nl (E.H.M. Moors).
}

for the environment, resulting in unnecessary $\mathrm{CO}_{2}$ emissions (HLPE, 2014), loss of biodiversity, deforestation and squandering of water and fertile soil (FAO, 2013). To stimulate the reduction of food waste and losses, the United Nations General Assembly adopted in 2015 the target of halving food losses and waste per capita along FSCs, under the Sustainable Development Goal (SDG12) of Responsible consumption and production (UN, 2016). Such ambitious target in combination with civil society demands for sustainably produced food has been challenging companies, governments and research institutions to explore innovative options to reduce food losses and waste across FSCs (FAO, 2011; Lipinski et al., 2013). The quest for efficiency and sustainability within FSCs is thus no longer an isolated endeavor of a few, but rather the collaborative effort of social, 
institutional and corporate networks mutually influencing each other (Lambert et al., 1998).

A distinction is made between food losses and food waste; food losses refer to food that "spills, spoils, incurs an abnormal reduction in quality such as bruising or wilting, or otherwise gets lost before it reaches the consumer" (Lipinski et al., 2013:1). Such losses are often a consequence of poor infrastructure, technology, transportation, refrigeration and packaging (Gustavsson et al., 2011), as well as the lack of collaborative relationships between key segments of the market (Barratt, 2004). Food waste is described as "food that is of good quality and fit for human consumption but that does not get consumed because it is discarded, either before or after it spoils" (Lipinski et al., 2013:1). The food losses and waste that occur after harvesting and before reaching the consumer, i.e., postharvest losses (PHL) are of particular interest, since addressing losses early in the FSC would avoid the environmental, social and economic costs that add up with every additional step of the FSC (FAO, 2013). The reduction of PHL is therefore increasingly recognized as crucial to the sustainability of food supply chains (Kiaya, 2014). Postharvest losses refer to food that get lost after harvest, through crop processing, distribution marketing and retailing, just before reaching the consumer (Hodges et al., 2011). Food discarded at the consumer level is regarded as food waste and is not part of PHL. Reducing PHL could save economic resources of farmers and companies, increase the availability of food, and reduce the pressure on the natural resources needed to grow food (WRI, 2016). In global FSCs the focus of postharvest losses lies on developing countries since it is there where avoidable PHL are the highest (HLPE, 2014).

Trienekens and Willems (2007) assert that innovation in FSC is regarded a key component of sustainable solutions. However, according to Barratt (2004) most FSC investments focus heavily on mechanical and technological innovations. Leach et al. (2012) argue that to meet ambitious Sustainable Development Goals, such as halving global food losses and waste by 2030 , not only new technologies are required, but also innovations that give more recognition and credibility to the people involved. Pippel (2014) asserts that structural innovations in organizations are often required to enhance technological innovations.

Innovation literature highlights the importance of collaborative relationships to innovate (Soosay et al., 2008), while sustainability literature considers structural innovations within organizations (Trienekens and Willems 2007) and inclusive systemic approaches (Vermeulen and Witjes, 2016) as cornerstones of sustainable food supply chains. However, these concepts are underrepresented in literature on postharvest losses within global FSCs, as it mainly focuses on the technological aspects of postharvest losses (Barratt, 2004). Consequently, in this study we focus on the social aspects leading to structural inefficiencies in the food supply chain, providing an insight into the ways in which collaborative innovation can reduce postharvest losses. Kaipia et al. (2013), Lambert and Cooper (2000), Simatupang and Sridharan (2002) and Faems et al. (2005) have found that FSC participants find it challenging to collaborate effectively, especially in global supply chains. They argue that complementing technological innovations with new ways of collaboration could improve productivity and reduce structural inefficiencies.

\subsection{Innovative collaboration}

Soosay et al. (2008) mention the concept of innovative collaboration in the contexts of collaborative relationships, efficient allocation of resources, and firms' capabilities to innovate in collaboration with other participants of the FSC. Kaipia et al. (2013) stress the importance of new forms of collaboration by pointing out that postharvest losses in perishable food supply chains can be reduced by FSC participants sharing information more efficiently and engaging in new partnerships. In global food supply chains for example, importers need to collaborate with FSC participants across borders regarding production, storage, and transportation. The perishability of some food products adds to the complexity of FSC management whereby fast delivery lead times are expected. At the same time, collaboration can be affected by different means of working across different geographies. For example, in LatinAmerican countries, business communication takes place largely through email and fax, while in many European companies the use of Electronic Data Interchange (EDI) is the norm.

Lambert and Cooper (2000) argue that successful supply chain management requires a cross-functional integration of material and information flows as well as strategic partnerships. Simatupang and Sridharan (2002) suggest that new forms of collaboration in which information is exchanged across the FSC would eliminate the need of making educated guesses, thereby improving decision-making and efficiency. They further recognize that conflicts in the FSC can be avoided by aligning the incentives of individual FSC participants to benefit the whole FSC. Likewise, Soosay et al. (2008:160) argue that "business with a supply chain strategy require integration, cooperation and collaboration, which in turn demand aligned objectives, open communication, sharing of resources, risks and rewards". Faems et al. (2005) state that FSC participants can improve their capabilities by engaging in new partnerships, improving their use of existing technology or developing new technology. Arnold (2017) argues that innovating in collaboration is especially relevant in FSCs with many participants, since it can stimulate a chain-based thinking through which the people involved can interact, discuss and negotiate to create sustainable outcomes in the interest of all.

Based on the insights of these authors, innovative collaboration is defined here as the improvement or creation of interorganizational relationships through which FSC participants can (1) exchange information, (2) align incentives, (3) engage in effective partnerships, and (4) improve their use of technology.

Accordingly, the main aim of this study is to understand how innovative collaboration influences the sustainability of global food supply chains through the reduction of postharvest losses. To do so, we have defined three objectives: First, to provide a clear understanding on how participants in global food supply chains interact with each other; second, to identify the structural inefficiencies leading to postharvest losses along the supply chain, and third, to identify the main drivers and barriers of FSC participants to engage in collaborative innovation. Our main contribution is a typology of structural inefficiencies in the avocado supply chain, which provides insight into the social drivers of postharvest losses along global food chains.

This article is structured as follows: Section 2 discusses postharvest losses and sustainable food supply chains. Furthermore, it discusses the theoretical background and main components of innovative collaboration: information exchange, incentives' alignment, effective partnerships and adequate use of technology. Section 3 presents the selected cases and the methodology. Two case studies explore the supply chains of export avocados from Mexico and Colombia to the Netherlands. Section 4 presents the results of the case studies and indicates implications for future research. Finally, section 5 provides concluding remarks on the influence of innovative collaboration on the sustainability of global food supply chains.

\section{Postharvest losses and sustainable food supply chains}

We define sustainable food supply chains as a network of people collaborating to manage material, information and capital flows 
(Seuring and Müller, 2008), while generating the greatest possible value with the lowest possible environmental, social and economic impacts.

The HLPE (2014) identifies two types of impacts caused by postharvest losses: explicit impacts and opportunity impacts. Explicit impacts are related to the existence of a physical flow of PHL, while opportunity impacts are viewed as the economic, social or environmental lost value in reference to a better alternative with less PHL. Hodges et al. (2011) observe that these impacts get exacerbated within global FSCs, in which more FSC participants are involved within different economic and institutional contexts, some of which are already weakened by other contextual factors.

In this context they notice that FSC participants in developing countries are more susceptible to both kinds of impacts, since in many cases their livelihood and food safety are negatively affected by postharvest losses. Accordingly, most studies on postharvest losses show that reducing them would not only increase the sustainability of FSCs but also the sustainability of food systems, which encompass the institutional and policy conditions in which FSCs exist (HLPE, 2014). As the HLPE (2014) points out, most of today's analyses agree that a reduction of PHL would lead to FSCs being more sustainable, with positive economic, social and environmental outcomes, outweighing the cost of action. An optimum and realistic outcome for sustainable FSC is not zero PHL, but a situation in which avoidable PHL are not a byproduct of FSCs.

Reducing PHL through innovative collaboration entails tackling the structural inefficiencies that refrain FSC participants from working towards the same objectives, with symmetric information and proportional rewards. Section 2.1 presents the structural inefficiencies leading to PHL along FSCs. Next, section 2.2 describes the concept of innovative collaboration and its components.

\subsection{Structural inefficiencies leading to avoidable postharvest losses along food supply chains}

Structural inefficiencies are defined here as flaws within the large set of managerial decisions, commitments, incentives and human relationships leading to PHL along FSCs. We argue that structural inefficiencies can lead to avoidable postharvest losses within food supply chains, thereby being a barrier for the sustainability of FSC.

Structural inefficiencies at the individual and company level can compromise the organization's ability to operate sustainably. For example, when companies work in silos, the technological innovations they implement might lead to lower product price rather than to higher income for farmers, thereby disincentivizing them to improve product quality or agricultural practices (HLPE, 2014).

Structural inefficiencies at the FSC level can have impacts at a different stage of the FSC than where they were originated, and often determine the existence or extent of structural inefficiencies at the individual or company level. For example, inadequate manipulation of fruit early in the FSC due to deficient agricultural practices, can lead to a shorter product shelf life at the retail and consumer level (HLPE, 2014). Likewise, last minute changes in procurement decisions by retailers or importers could lead to sudden surplus stocks and bring prices down, thereby eliminating the incentive of other FSC participants to keep the product in the FSC, ultimately leading to PHL (HLPE, 2014).

Structural inefficiencies at the institutional level limit the extent to which FSC participants collaborate, invest and adopt good practices. In practice, PHL are usually the result of an interrelation of structural inefficiencies at all levels, especially since actions at one level can impact the whole FSC (HLPE, 2014). Table 1 shows the impact on the social, environmental and economic dimensions that result from these structural inefficiencies.
Table 1 is by no means exhaustive, but it highlights that structural inefficiencies along FSCs arise especially due to inadequate managerial decisions, commitments, incentives and human relationships along FSCs resulting, among others, from the lack of (1) information exchange, (2) incentives alignment (3) effective partnerships or (4) the inadequate use of technology among FSC participants (Faems et al., 2005; Gustavsson et al., 2011; Hodges et al., 2011; Kaipia et al., 2013; HLPE, 2014). At the FSC level, logistic improvements would certainly alleviate many of these inefficiencies; however, according to the HLPE (2014) these should be applied while having knowledge of the specific local geographical, cultural and economic conditions of the users. Collaboration among FSC participants can facilitate the gathering of such knowledge by increasing transparency and improving the quality and amount of collected data. In this context, innovative collaboration could spur quantitative and qualitative analysis, communication and knowledge dissemination towards the reduction of postharvest losses (HLPE, 2014).

\subsection{Innovative collaboration within food supply chains}

Structural inefficiencies not only lead to a waste of valuable resources, but also create friction between food supply chain participants (Lambert and Cooper, 2000), which in turn can lead to further waste of resources. Innovative collaboration involves the reduction of such friction between FSC participants, by improving or creating inter-organizational relationships through which they can agree to jointly make decisions, solve problems, align their goals and exchange resources, rewards, responsibilities and information (Soosay et al., 2008). Consequently, innovative collaboration is defined here as the improvement or creation of interorganizational relationships through which FSC participants can exchange information, align incentives, engage in effective partnerships and improve their use of technology. These will be briefly discussed below.

\subsubsection{Information exchange}

Exchanging information has been suggested to be one of the most important means to reduce food losses and waste along FSC (Lambert and Cooper, 2000; Kaipia et al., 2013). Yet, the reticence of FSC participants to exchange information is also one of the most challenging structural inefficiencies along FSC (Pibernik et al., 2011). The fear of FSC participants of losing competitive advantages, being exposed to opportunism and losing bargaining power, refrain them from sharing sensitive data (Lee and Whang, 2000; Pibernik et al., 2011). Kaipia et al. (2013) assert that overcoming this limitation is key to the reduction of postharvest losses along FSC. Information exchange is defined as the mutual, proactive, regular and timely share of information (tacit and explicit knowledge) that is relevant and clear to FSC participants (Coronado et al., 2010; Pibernik et al., 2011). Information exchange contributes to reduce uncertainty of demand and supply, improve coordination and planning (Lee and Whang, 2000), reduce costs, and enhance overall supply chain performance (Kaipia et al., 2013), all of which could contribute to the reduction of PHL.

\subsubsection{Incentive alignment}

Lack of incentive alignment arises due to attitudes that are contingent upon short-term results (FAO, 2004), and due to companies lacking the means or sense of importance to resolve their cultural, economic and organizational differences in order to align their policies, priorities, definitions, perceptions and long-term objectives (Simatupang and Sridharan, 2002). The quality of the product, for example, is important for all FSC participants; however, FSC participants may have different definitions or perceptions of 
Table 1

Impacts of structural inefficiencies leading to postharvest losses at the individual company, food supply chain and institutional levels.

\begin{tabular}{|c|c|c|c|c|c|}
\hline \multirow{2}{*}{\multicolumn{2}{|c|}{$\begin{array}{l}\text { Structural inefficiencies } \\
\text { leading to postharvest } \\
\text { losses }\end{array}$}} & \multicolumn{4}{|l|}{ Impacts } \\
\hline & & Social (a) & Environmental (b) & Economic (c) & Source \\
\hline \multirow{3}{*}{\multicolumn{2}{|c|}{$\begin{array}{l}\text { Individual and } \\
\text { company level }\end{array}$}} & $\begin{array}{l}\text { Lower wages for FSC participants in developing } \\
\text { countries }\end{array}$ & $\begin{array}{l}\text { More garbage and waste and } \\
\text { increased number of landfills }\end{array}$ & $\begin{array}{l}\text { Lost investment for business and } \\
\text { consumers when purchased food is } \\
\text { lost or wasted. }\end{array}$ & a, b, c: HLPE, 2014 \\
\hline & & Lower consumer purchasing power & $\begin{array}{l}\text { Contamination of rural and urban } \\
\text { areas }\end{array}$ & $\begin{array}{l}\text { Smaller margins and high prices, } \\
\text { which in turn lead to lower } \\
\text { consumption }\end{array}$ & $\begin{array}{l}\text { a, b: HLPE, 2014; } \\
\text { c: Antunes et al., } \\
2007\end{array}$ \\
\hline & & Lower availability of food & & & $\begin{array}{l}\text { a: Gustavsson } \\
\text { et al., 2011; } \\
\text { Kummu et al., } 2002\end{array}$ \\
\hline \multirow[t]{6}{*}{$\begin{array}{l}\text { Food } \\
\text { suppy } \\
\text { chain } \\
\text { level }\end{array}$} & $\begin{array}{l}\text { Lack of } \\
\text { information } \\
\text { exchange }\end{array}$ & Uncertainty of demand & $\begin{array}{l}\text { Waste of valuable natural } \\
\text { resources }\end{array}$ & $\begin{array}{l}\text { Uncertainty of supply and } \\
\text { production flows }\end{array}$ & $\begin{array}{l}\text { a: Lee and Whang, } \\
\text { 2000; } \\
\text { b: Lambert and } \\
\text { Cooper, 2000; c: } \\
\text { HLPE, } 2014\end{array}$ \\
\hline & $\begin{array}{l}\text { Lack of } \\
\text { incentives } \\
\text { alignment }\end{array}$ & Low labor productivity & $\begin{array}{l}\text { Low compliance with } \\
\text { environmental regulations }\end{array}$ & $\begin{array}{l}\text { Increased costs and decreased } \\
\text { overall supply chain performance }\end{array}$ & $\begin{array}{l}\text { a: HLPE, 2014; } \\
\text { b: Tielens and } \\
\text { Candel, 2014; c: } \\
\text { Kaipia et al., } 2013\end{array}$ \\
\hline & & Lack of application of best practices & $\begin{array}{l}\text { Mismanagement of natural } \\
\text { resources }\end{array}$ & Unforeseen investments & a,b,c: HLPE, 2014; \\
\hline & $\begin{array}{l}\text { Lack of } \\
\text { effective } \\
\text { partnerships }\end{array}$ & $\begin{array}{l}\text { Increased power and influence of retailers and } \\
\text { traders over farmers "with farms squeezed by new } \\
\text { forms of governance of value chains" }\end{array}$ & & $\begin{array}{l}\text { Increased costs of disposal and } \\
\text { treatment of waste }\end{array}$ & $\begin{array}{l}\text { a: Lang and } \\
\text { Barling, 2012:316 } \\
\text { c: HLPE, 2014; }\end{array}$ \\
\hline & $\begin{array}{l}\text { Inadequate } \\
\text { use of } \\
\text { technology }\end{array}$ & Increased time investment and lower productivity & $\begin{array}{l}\text { Inefficient use of energy and } \\
\text { resources }\end{array}$ & Decreased product quality & $\begin{array}{l}\text { a,b: HLPE, 2014; c: } \\
\text { Lambert and } \\
\text { Cooper, } 2000\end{array}$ \\
\hline & & & Unnecessary $\mathrm{CO}_{2}$ eq emissions & $\begin{array}{l}\text { Long term unviability of current } \\
\text { food business model }\end{array}$ & b,c: HLPE, 2014 \\
\hline \multirow{5}{*}{\multicolumn{2}{|c|}{ Institutional level }} & Increased food prices in food insecure regions & $\begin{array}{l}\text { Increased water footprint and } \\
\text { pressure on soil, land and } \\
\text { biodiversity }\end{array}$ & $\begin{array}{l}\text { Increased spending on production, } \\
\text { distribution }\end{array}$ & $\begin{array}{l}\text { a: HLPE, 2014; } \\
\text { b: FAO, 2013, HLPE, } \\
\text { 2014; } \\
\text { c: Lang and Barling, } \\
2012\end{array}$ \\
\hline & & More people below the poverty line & $\begin{array}{l}\text { Increased use of non-renewable } \\
\text { energy and increased emissions } \\
\text { of greenhouse gases }\end{array}$ & Unrealized economic targets & a, b, c: HLPE, 2014; \\
\hline & & & $\begin{array}{l}\text { Intensified use of forests and } \\
\text { conservation areas for food } \\
\text { production }\end{array}$ & $\begin{array}{l}\text { Less financial resources for } \\
\text { investment in other areas }\end{array}$ & b, c: FAO, 2013; \\
\hline & & & $\begin{array}{l}\text { Roughly } 1 / 4 \text { of all water and } \\
\text { cropland are used to produce } \\
\text { food that is lost or wasted }\end{array}$ & $\begin{array}{l}\text { Roughly } 1 / 4 \text { of all fertilizer is used } \\
\text { to produce food that is lost or } \\
\text { wasted }\end{array}$ & $\begin{array}{l}\text { b,c: Kummu et al., } \\
2012\end{array}$ \\
\hline & & & $\begin{array}{l}\text { Increased use of synthetic } \\
\text { fertilizers that affect biodiversity } \\
\text { and water quality }\end{array}$ & $\begin{array}{l}\text { Decreased productivity of public } \\
\text { investment in agriculture, } \\
\text { becoming an opportunity cost }\end{array}$ & $\begin{array}{l}\text { b: Kummu et al., } \\
\text { 2012; } \\
\text { c: HLPE, } 2014\end{array}$ \\
\hline
\end{tabular}

quality which can lead to uncoordinated handling of the product, resulting in PHL (Arpaia, 2005). Growers may perceive quality as the absence of diseases, optimal size and return of investment; packinghouse handlers, wholesale distributors, and retailers, may perceive quality as the ease of handling, uniformity of packaging and absence of physical and physiological defects (Arpaia, 2005), while importers may perceive it as the freshness of the product and the timely delivery of their demand. Incentive alignment involves FSC participants making decisions that consider rewards beyond their own gate and that maximize overall supply chain profitability through a regular assessment of objectives (Simatupang and Sridharan, 2002), while sharing the costs, risks and benefits entailed with collaboration (Hudnurkar et al., 2014). Additionally, it entails a cultural, economic and organizational alignment through which differences between FSC participants are first acknowledged in order to be able to use them to the advantage of the FSC (Durnell Cramton and Hinds, 2014).

\subsubsection{Effective partnerships}

A retailer purchasing from a global FSC needs reliable partners
(Ziggers and Trienekens, 1999). Likewise, farmers need reliable markets and the opportunity to negotiate practical rules and regulations (Smith, 2008). An effective partnership is an alliance between FSC participants characterized by its capacity to avoid knowledge spillovers, learning races between the partners, diverging opinions on intended results, and lack of flexibility and adaptability (Faems et al., 2005). Effective partnerships can increase the mutual trust, respect and reliability of FSC participants, thereby contributing to increased openness and transparency along the food supply chain (Smith, 2008). Ziggers and Trienekens (1999) recognize that effective partnerships can, (a) reduce transaction costs, risks and FSC structural inefficiencies, (b) enhance the FSC participants' ability to innovate and improve their market position, and (c) "[...] have a profound contribution to a sustainable competitive advantage" (p.278).

\subsubsection{Adequate use of technology}

In global FSCs, the challenge lies especially in overcoming structural inefficiencies, rather than technological ones; although proper technology and infrastructure are a necessity, having them 
does not guarantee their adequate use. Faems et al. (2005) assert that collaboration among FSC participants could take existent technologies and competences to a further level of development but also stir the development of new ones. Coronado et al. (2010) found that improving the competences of FSC participants and their knowledge in how to use technology and infrastructure (through clear use' instructions, training to handlers and using best handling practices), has a positive impact on the accuracy of planning deliveries, stir the adoption of complex quality standards, and stimulate the use of best practices, such as cold chains. An empirical example is the increased energy inefficiency caused by the introduction of cooling technology at the back-end of the FSC without further structural changes: due to lack of trust regarding cooling practices in other parts of the FSC, each preceding FSC participant would unnecessarily maximize cooling, thereby wasting energy and decreasing product's quality. The adequate use of technology is thus underpinned by the capacity of FSC' participants to overcome structural inefficiencies.

The concepts of the theoretical framework are combined into a conceptual model, as presented in Fig. 1. The left part of the model shows the FSC participants of a conventional food supply chain: suppliers, producers, packers, storage workers, transporters, exporters, importers, retailers and consumers. It is hypothesized that when FSC participants engage in innovative collaboration by means of information exchange, incentives alignment, effective partnerships and adequate use of technology, there is a positive influence on the sustainability of the FSC through the reduction of PHL.

\section{Methods}

This section describes the case studies (3.1) followed by the research's design and execution of main concepts (3.2). Subsequently, it presents the method of data collection (3.3) and data analysis (3.4).

\subsection{Case description}

The highest percentages of postharvest losses take place in FSCs of perishable products and especially of fresh fruits and vegetables (Gustavsson et al., 2011). The chosen unit of analysis of this research is the global supply chain of avocados. The rationale for this choice is twofold: (1) Europe's fast-growing import of avocados from developing countries (roughly 300,000 tons in 2015), has shown

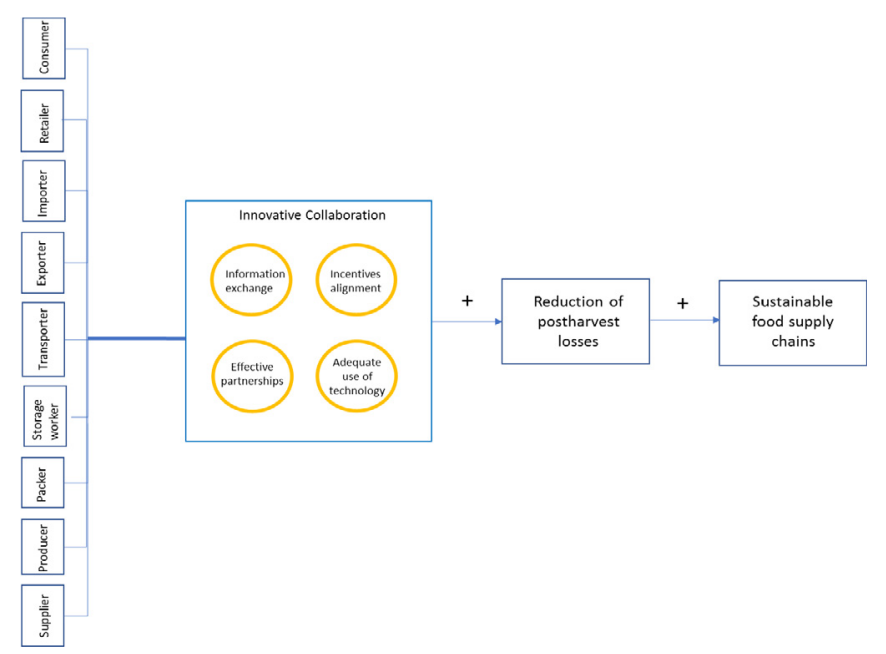

Fig. 1. Conceptual model showing the relationships between FSC participants' innovative collaboration, postharvest losses and sustainability. over $40 \%$ increase in volume in the last five years; this upward trend has been especially driven by the growing demand of European consumers for healthy food (CBI, 2015). (2) Avocados are known to be highly susceptible to postharvest losses (Bill et al., 2014). Losses and waste of avocados are estimated to be of about $5-25 \%$ in developed countries and of about $20-50 \%$ in developing countries (FAO, 2004). Notwithstanding the lack of a most recent source for these estimates, it is assumed that postharvest losses of avocados are within the range of overall losses and waste of fruits and vegetables, which have not been ameliorated in the last decade, being 42\% in 2009 (Lipinski et al., 2013), 45\% in 2012 (FAO, 2013) and expected to increase in absolute terms along with increased production. As case studies, the food supply chains of avocados exported from Mexico and Colombia into Europe and in particular into The Netherlands, have been chosen due to the following reasons: The Netherlands is the major trade hub for avocados to other European countries, accounting for roughly a third of total EU avocado imports; from the 300,000 tons imported in 2014, about $85 \%$ originated in developing countries (CBI, 2015). Both exporting countries have similar demographic (The World Bank, 2016a, b) and logistic conditions (The World Bank, 2016c) of avocado production. Mexico is an established avocados producer, producing roughly $50 \%$ (BBC, 2016), of the global avocado production, while Colombia is a new incumbent, producing $5 \%$ of total global production (Minagricultura, 2014), thereby allowing for analysis regarding the influence of production-and-export on postharvest losses. Additionally, Mexico and Colombia have become direct competitors in the avocado export market due to their similar annual production calendars (see Fig. 2) (LKS, 2013).

Since measurements of PHL are still primitive and known quantities widely differ, the influence of innovative collaboration on the sustainability of the FSC through the reduction of postharvest losses is qualitatively assessed through the perceptions, visions and interactions of FSC participants. This research is not designed to compare these countries, but rather to find a replication of patterns (or a lack thereof), whenever innovative collaboration is present.

\subsection{Research design and execution}

This research takes a qualitative approach in exploring innovative collaboration within food supply chains, as innovative collaboration is rather ill understood and cooperation between actors is important (Marshall and Rossman, 1995). Understanding innovative collaboration requires thus a detailed and interpretative analysis, that also considers characteristics of the specific context in which it appears (e.g. Lee, 1999; Garud et al., 2002). Theoretically, it draws on the four concepts of innovative collaboration: information exchange, incentives alignment, effective partnerships and adequate use of technology. In understanding how innovative collaboration influences sustainability of global food supply chains through the reduction of postharvest losses, this research distinguishes two research questions: First, how do FSC participants interact and which structural inefficiencies leading to postharvest

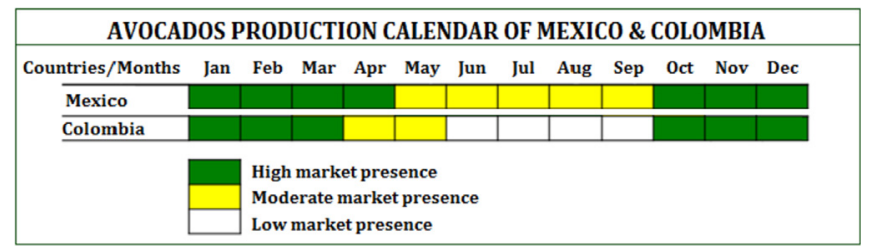

Fig. 2. Avocados production calendar of Mexico and Colombia. (Adapted from LKS 2013). 
losses can be identified in global food supply chains? And second, what are the main drivers and barriers of FSC participants to engage in innovative collaboration to reduce postharvest losses within global food supply chains? Fig. 3 presents the operationalization and describes how the four innovative collaboration concepts are studied. The indicators were used as sensitizing concepts for the interview questions. Specifically, this research is designed to explore patterns, perceptions, behaviors, attitudes, interactions and relations underlying both the structural inefficiencies that lead to PHL and the capacity of FSC participants to engage in innovative collaboration. This is done to elucidate whether exchanging information, aligning incentives, engaging in partnerships and enhancing the ways in which technologies are used along FSCs contribute to address the structural inefficiencies that lead to postharvest losses.

\subsection{Data collection}

For the collection of data, scientific literature and available documentation of companies were consulted. 25 semi-structured interviews were held with experts and FSC participants. Based on the theoretical framework, interview questions were prepared (see appendix A).

Identification of interviewees for this study was a two-stage process in which purposive sampling of initial interviews was complemented by snowball sampling. For the two cases, 25 people were identified as valuable respondents for in-depth qualitative interviews (see appendix B, including reference numbers ${ }^{[1}$ through ${ }^{25]}$ ). The interviews with interviewees based in the Netherlands (13) were held face to face, whereas interviews with interviewees based in Mexico (7) and Colombia (5) were done by phone. Different stages of the FSC were represented by the interviewees: Import (8), production/export (6) growers' associations (2), governmental organizations (3), packer (1) and knowledge institutions (5 interviewees).

\subsection{Data analysis}

The collected data from interviews, documents and literature was coded using the software NVIVO10, which facilitates the identification and examination of relationships in the data, thereby allowing comparisons between literature and empirical findings. In NVIVO, the collected data from interviews, documents and literature was structured through a coding process through which patterns in the data were discerned to generate nodes. Initial topic nodes were named after each of the main concepts of this research, namely sustainable food supply chains, postharvest losses,
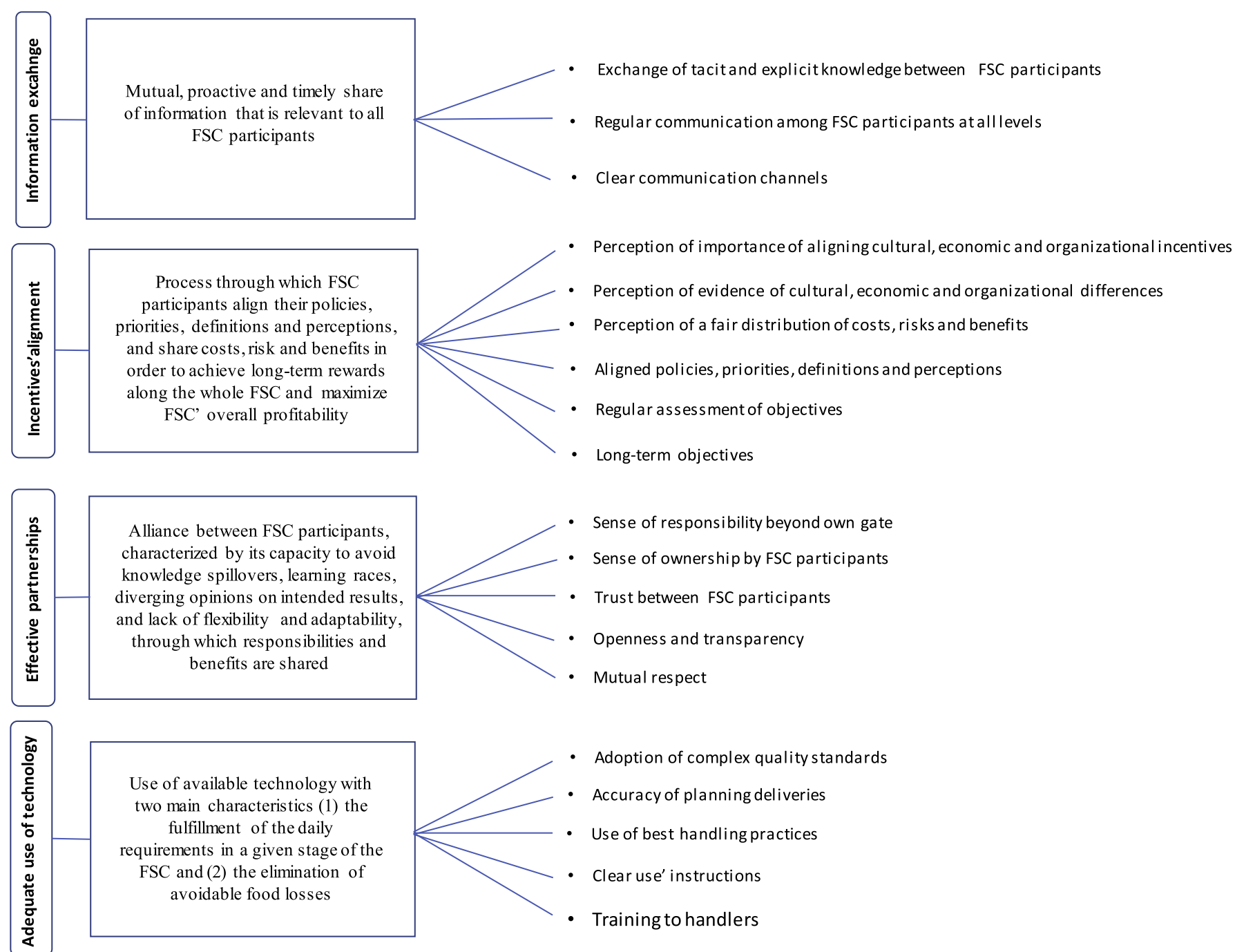

Fig. 3. Concepts of innovative collaboration. 
information exchange, incentives alignment, effective partnerships and adequate use of technology. Each of these topic nodes was described using the definitions of the concepts presented in the theoretical framework, into which selected pieces of data relevant to a specific node were categorized. In cases in which frequently repeated information could not fit into one of the initial nodes, secondary nodes were created. In cases in which data already categorized into a certain node lent itself to be further divided into sub-categories, sub-nodes were created. Through a case node, the data was demographically classified between the Mexican and the Colombian supply chains based on the FSC participants' home base, coded in NVIVO as an attribute with the values, Mexico or Colombia. Through the classification of the data, a coding tree was created upon which the results of the research were structured.

The categorization of the data allowed the following analysis structure with four steps in a funnel-like fashion. First, the results were analyzed on a global scale, identifying general interactions and relationships among FSC participants. Second, the results were analyzed within the context of the case study, which allowed for the identification of patterns, structural inefficiencies, and barriers and drivers of innovative collaboration within the two FSCs. The third part of the analysis involved selecting and bringing together all findings relevant to each component of innovative collaboration to bring analytical depth to the conceptual understanding of the findings. The interviews in the Netherlands were held in Dutch. These were recorded, translated to English and transcribed by the author. The interviews in Mexico and Colombia were held in Spanish. These were likewise recorded, translated by the author and transcribed in English. Five of the interviews were held with experts on fresh food supply chains (2), food losses and waste (1), innovation (1) and management studies from which we received feedback iteratively during the writing of our findings. The interpretation of the data, i.e. the transcripts of the interviews or pieces of interviews, was shared with other interviewees whenever further clarification was needed. After the data analysis, a concept document of the research was shared with two interviewees willing to provide comments or suggestions.

\section{Results and discussion}

Section 4.1 presents the structural inefficiencies leading to postharvest losses in the Mexican and Colombian avocado supply chains. Section 4.2 gives the findings on the main drivers and barriers of FSC participants to engage in innovative collaboration to reduce postharvest losses. Section 4.3 focuses on reducing postharvest losses through innovative collaboration.

\subsection{Vertical and horizontal collaboration in the global avocado supply chain}

Food supply chain participants interact through both horizontal collaboration driven by competition, and vertical collaboration driven by the inherent need in FSCs of getting a product from the field to the consumer. Horizontal collaboration is considered to be strategically advantageous, as FSC participants get to exchange the kind of information that is beneficial for the whole supply chain and whose exchange does not entail a competitive disadvantage for any FSC participant. Vertical collaboration is considered to be functionally essential as it leads to, (a) cost savings from increased efficiency due to recurrent procedures that become habitual, (b) reduced transactional friction due to regular communication, (c) increased alignment of the organizational culture, and (d) increased risk-taking attitudes towards innovation due to risksharing practices between FSC participants; all of which have the potential to contribute to the reduction of postharvest losses. In line with Faems et al. (2005) interviewees emphasize that long term vertical collaboration increases the stability of the relationship, enhances existing competence and improves their innovative performance. An importer asserts: "Not having to constantly worry about the reliability of daily transactions increases our flexibility to innovate in the way we interact with our partners, such as planning promotions together, setting up pricing mechanisms that benefit us both, or jointly optimizing the chain to reduce product losses" [3]. However, collaborating vertically is done with caution in order to avoid exchanging information that potentially increases the competitive advantage of others at expenses of the own.

Inter-personal interactions seem to be very important in paving the way towards more formal and long-term relationships. As relationships evolve, structural inefficiencies are gradually removed from the food supply chain due to positive behaviors becoming embedded in the organizational culture of FSC participants. Three main types of structural inefficiencies were found: (1) corporate inefficiencies, which are flaws in, the processes, corporate structures and managerial mechanisms underlying the coordination of activities along the food supply chain, thereby leading to postharvest losses, (2) cognitive and affective inefficiencies, which are perceptions, expectations, beliefs, emotions, values, behaviors and feelings of FSC participants leading to postharvest losses along the food supply chain, and (3) tangible inefficiencies, which are infrastructural or operational flaws in the production, in the use of resources or in the handling of the product leading to postharvest losses along the food supply chain. Most of the found structural inefficiencies in both case studies are of the corporate category, suggesting that the well-functioning of the FSC is highly dependent on the enabling environment created by the food system in which the FSC exists. This is in line with Kaipia et al. (2013)'s assertion that improving sustainable performance requires changes in the whole supply chain rather than merely there where the problem occurs.

\subsection{Structural inefficiencies leading to avoidable postharvest losses in the global avocado supply chain}

\subsubsection{Mexico}

A main structural inefficiency identified in the Mexican avocado industry is the lack of overseas export expertise, which is paradoxically due to two main comparative advantages of the country: (1) the high domestic demand of roughly $10 \mathrm{Kg} /$ person/year and the US demand of roughly 3,5Kg/person/year (Agricultural Marketing Resource Center, AgMRC, 2016), which by creating a secure market for producers, have until recently, limited the urgency and willingness to produce for other export markets ${ }^{[3]}$ (2) The "effortless" premium quality and superior taste of export avocados that grow in Mexican volcanic soil, for which, according to an importer, "there will be always nearby buyers willing to pay premium prices" [3]. According to an expert in management studies, this in turn, reduces producers' motivation to increase yields ${ }^{[21]}$, which are already inferior to those of other avocado producing countries (9MT/ha yield for the period 2015/mid 2016, compared to 10-18 MT/ha of Colombia) ${ }^{[1] .}$ Additionally, the current high return on investment in the avocado producing sector may discourage small and medium producers from incurring in further investments to improve yields, since "[... with a] fairly low yield [of 100 avocados a year] farmers can make as much as $\$ 500,000$ ( $£ 383,000$ ) annually from the plot" (The Guardian, 2016). An importer ${ }^{[5]}$ asserts that this privileged position of the Mexican avocado industry can be counterproductive since large producers have developed a limited willingness to adapt their product to new markets.

Interviewees stress the lack of attention from the Mexican avocado industry to the threat posed by competitors, especially new entrants from developing countries. An Organizational 
development manager asserts: "We have been so focused in our own competitive advantage for so long that we have not been paying enough attention to the incredible growth potential of new producers from countries like Peru, Colombia, Chili and South Africa" ${ }^{[19]}$. One importer ${ }^{[6]}$ asserts that the $\mathrm{EU}^{\prime}$ demand from these countries has been steadily increasing, especially due to the higher yields of their harvest and lower PHL during shipping compared to Mexico's. Nonetheless, the president of the Mexican National Agricultural Council (CNA) stated recently that there are currently no strong competitors for Mexican avocados in the international market, due to the country having the largest producing area and most of the total demand (Diario ABC de Michoacan, 2016). In this respect, a commercial consultant asserts that underestimating the competition discourages people from investing in improvements of processes and products: "Resting in our laurels is not the way to stay competitive [...] and to reduce the inefficiencies of our production we'll need to do more than just the usual" ${ }^{[15]}$.

\subsubsection{Colombia}

Due to the early stage of development of the Colombian avocado industry, small and medium producers are still poorly structured, with a very high failure rate of new small productions enterprises, and with a low or inadequate legal regulatory framework offered by cooperatives (LKS, 2013). A structural inefficiency often mentioned by interviewees is the lack of standardization of harvest and postharvest processes. Most small and medium producers produce avocados with great variations in sizes, appearance and quality, being thereby of less interest for most large exporters to close long term export agreements ${ }^{[11,12]}$. An exporter asserts that "much of the avocado produced for export gets disqualified due to their lack of uniformity, which is in turn caused by a lack of awareness among small and medium producers regarding the benefits of adapting their product for the export market" [12]. To avoid the complexities of export, many producers still prefer to focus on the domestic market, which presents a high and unsatisfied demand. However, production for domestic markets takes place under less strict phytosanitary and quality conditions, thereby resulting in PHL of roughly $40-50 \%$ caused largely by pests and diseases, lack of infrastructure and materials and inadequate inland transport conditions. Fig. 4 shows the typical way in which production for domestic markets is packed and transported, causing an increased risk of injury and postharvest losses.

An investment specialist asserts: "The quality of our product is highly dependent on the infrastructural conditions of the country; the whole avocado chain must therefore work hand in hand with the government to plan and carry out infrastructural improvements, as well as be willing to invest in them if we don't want to see the export potential of the industry hampered" ${ }^{\text {"16] }}$. Nonetheless, investments, financial support and credits in the avocado chain increased more than 250\% from 2010 to 2013 (Minagricultura, 2014), while

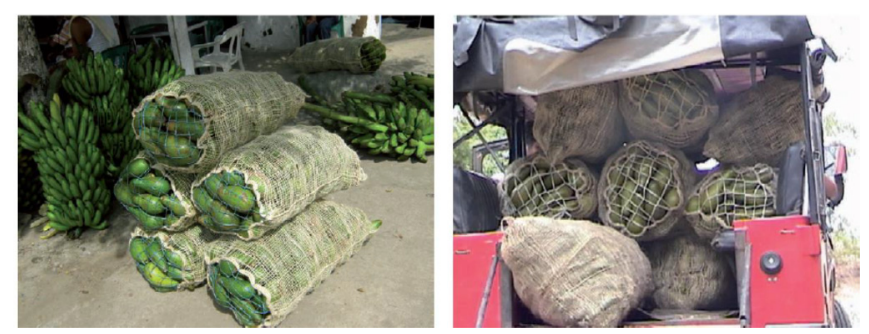

Fig. 4. Inadequate packing (left) and transport (right) conditions of avocados for the Colombian domestic market. Avocados are not held under controlled temperature and are susceptible to bruising and insects, leading thereby to postharvest losses (Source: Corpoica Colombia, 2010). investments in transport with private participation have been rapidly increasing, reaching almost 12 US billion dollars in 2015 (World Bank, 2016a,b,c).

Interviewees point out the dependence of small and medium producers to the national market caused by a "lack of training and support to produce avocados suitable for export" [10]. The Executive director of a producer/exporter company points out that due to the high international demand, local governments of avocado producing regions have been trying to stimulate the production of Hass by giving seedlings to producers, but "in some cases, no further recommendations or training on the specific treatment of this avocado variety was offered to them" [11]. In line with this, interviewees identify a lack of effective monitoring and of monitoring tools along the whole supply chain, but especially when it comes to small and medium producers ${ }^{[1,9,11,12,16]}$. Some interviewees consider that the culprits of many structural inefficiencies are the high production cost of implementing monitoring systems ${ }^{[12]}$ and the instability of the production that impedes the audit of processes ${ }^{[16]}$, while the global consultancy LKS (2013) stress the high segmentation of the production, partly caused by the difficult access to land and unregulated land tenure (LKS, 2013).

Table 2 shows the findings on the structural inefficiencies in the Mexican and Colombian avocado supply leading to PHL. The structural inefficiencies found were subcategorized according to their underlying attributes. Corporate inefficiencies have been subcategorized into Managerial/Regulatory, Financial/Economic, and Knowledge/Information inefficiencies. Cognitive and affective inefficiencies have been subcategorized into Attitudes and Perceptions. Tangible inefficiencies have been subcategorized into Logistics/Distribution and Material/Sanitary inefficiencies.

Interviewees perceive importers to be powerful FSC participants as they are the gateway to a growing avocado market. Importers often decide what and from whom to buy, therefore they are expected to contribute to the reduction of avocado PHL by adopting more sustainably devised and responsible buying practices. Importers are already inclined to buy high quality avocados that are more resistant to the "hustle and bustle" entailed with export, which automatically leads to less PHL during export, but can however lead to PHL at the back-end of the FSC by eliciting a product selection based on aesthetic aspects. Without a more transparent approach to postharvest losses, interventions could only result in a shift of the stage of the FSC in which postharvest losses take place. By classifying the roots of these structural inefficiencies, this research also contributes to pointing the direction of needed interventions to reduce postharvest losses.

\subsection{Drivers and barriers of food supply chain participants to engage in innovative collaboration}

Differences in working culture and opinions are considered an important barrier to collaboration, often in the Mexican context $[2,4,6,13,15,18,19]$ and sometimes in the Colombian context $[3,10,16]$. Various participants downstream the FSC expressed their discontent due to the resistance to change of some producers and farmers ${ }^{[4]}$ and due to an increase in opportunistic behavior as exports from developing countries increase. An importer asserts: "The rapid pace of increase of exports does not match the pace at which organizational improvements in exporting countries take place [5]." An expert in management studies states that, "in such a business environment there is an increased risk of opportunism in the form of selling products of poor quality, delaying deliveries or not following through with agreements and contracts" [21]. Opportunism can also take place due to FSC participants having asymmetric extents of power and due to business strategies based on having such power. In this context a business developer asserts: "some buyers are awful; they think they 
Table 2

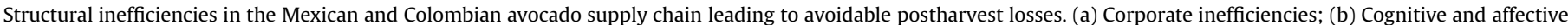
inefficiencies; (c) Tangible inefficiencies.

\begin{tabular}{|c|c|}
\hline $\begin{array}{l}\text { Mexico } \\
\text { a. } \\
\text { CORPORATE INEFFICIENCIES IN THE AVOCADO SUPP }\end{array}$ & $\begin{array}{l}\text { Colombia } \\
\text { LY CHAIN }\end{array}$ \\
\hline \multicolumn{2}{|l|}{ Managerial/Regulatory } \\
\hline $\begin{array}{l}\text { - Lack of organization of small and medium } \\
\text { producers } \\
\text { - Lack of supervision from regulatory bodies } \\
\text { - Unfulfilled commitments such as contract } \\
\text { conditions }\end{array}$ & $\begin{array}{l}\text { - Low or inadequate legal regulatory framework offered by cooperatives } \\
\text { - Segmentation and instability of production that difficult the audit of processes } \\
\text { - Low number of producers certified for export } \\
\text { - Lack of land ownership } \\
\text { - Lack of effective monitoring and of monitoring tools } \\
\text { - Preference for/dependence on domestic market due to less strict phytosanitary and quality conditions }\end{array}$ \\
\hline
\end{tabular}

\begin{tabular}{|c|c|}
\hline \multicolumn{2}{|l|}{ Economic/Financial } \\
\hline $\begin{array}{l}\text { - Importers' uncertainty of demand leading to • } \\
\text { overbuying } \\
\text { - Price variations that limit the planning potential } \\
\text { - Price mechanisms unadjusted for externalities } \\
\text { - Lack of attention to increased competition }\end{array}$ & $\begin{array}{l}\text { Organizational culture and business models misaligned with international markets } \\
\text { Uncertainty of demand leading to overbuying or underbuying }\end{array}$ \\
\hline \multicolumn{2}{|l|}{ Knowledge/Information } \\
\hline $\begin{array}{l}\text { - Lack of overseas export expertise } \\
\text { - Untrained staff }\end{array}$ & $\begin{array}{l}\text { Lack of standardization of harvest and postharvest processes } \\
\text { Lack of training to produce avocados suitable for export }\end{array}$ \\
\hline \multicolumn{2}{|l|}{ b. } \\
\hline \multicolumn{2}{|c|}{ COGNITIVE AND AFFECTIVE INEFFICIENCIES AVOCADO SUPPLY CHAIN } \\
\hline \multicolumn{2}{|l|}{ Attitude } \\
\hline \multicolumn{2}{|c|}{$\begin{array}{l}\text { - Limited willingness (small-medium producers) to }- \text { Low interest fror } \\
\text { invest in the improvement of production processes } \text { - Individualism an } \\
\text { and product } \\
\text { - Limited willingness to adapt product to new markets } \\
\text { - Limited motivation to increase yields }\end{array}$} \\
\hline \multicolumn{2}{|l|}{ Perception } \\
\hline \multicolumn{2}{|c|}{$\begin{array}{l}\text { - Disregard for environmental impacts caused by the } \begin{array}{ll}\text { - Lack of awareness among small and medium producers regarding the benefits of adapting their product for the } \\
\text { industry }\end{array} \\
\begin{array}{ll}\text { - Disregard of quality in forthcoming FSC stages } & \text { - Unawareness regarding the consequences of inadequate handling of the product } \\
\text { - Limited urgency for improved production } & \text { - Lack of status of small producers in international markets }\end{array}\end{array}$} \\
\hline \multicolumn{2}{|l|}{ c. } \\
\hline \multicolumn{2}{|l|}{ TANGIBLE INEFFICIENCIES AVOCADO SUPPLY CHAIN } \\
\hline \multicolumn{2}{|l|}{ Logistics/Distribution } \\
\hline $\begin{array}{l}\text { - Limited offshore transport infrastructure L\&D } \\
\text { - Inadequate containerization L\&D } \\
\text { - Lack of adequate offshore refrigeration or broken } \\
\text { cold chain L\&D } \\
\text { - Long shipping times (3-4 weeks) L\&D }\end{array}$ & $\begin{array}{l}\text { - Inadequate internal transport infrastructure L\&D } \\
\text { - Rough handling of boxes } \\
\text { - Broken cold chain due to inadequate inland transport L\& D } \\
\text { - Inadequate loading and overfilling of boxes }\end{array}$ \\
\hline \multicolumn{2}{|l|}{ Material/Sanitary } \\
\hline $\begin{array}{l}\text { - Alleged inadequacy of sanitary and phytosanitary } \\
\text { conditions }\end{array}$ & $\begin{array}{l}\text { - Use of contaminated vehicles (with fertilizers or chemicals) } \\
\text { - Inadequate phytosanitary conditions of domestic product } \\
\text { - Low level of mechanization, tool implementation and use of technological instruments by small and medium } \\
\text { producers } \\
\text { - Large variations in sizes, appearance and quality }\end{array}$ \\
\hline
\end{tabular}

can change their orders at any time" [2]. To avoid PHL due to sudden changes in product requirements from buyers and to ensure that suppliers take into consideration the quality expected by buyers, they are increasingly turning to Service Level Agreements (SLAs) [23]. SLAs are contracts between suppliers and buyers through which a common understanding regarding the minimum acceptable service and responsibilities is established. However, according to one interviewee ${ }^{[16]}$ SLA's are sometimes used as stopgaps for troublesome transactions and using them unaccompanied by longterm goals to improve the relationship, disregards the benefits entailed with strengthening the transparency and trust of the collaboration.

Several interviewees $[1,3,7,13,15,19,22,23]$ identified the lack of trust between FSC participants as one of the most important barriers to collaboration within the avocado FSC. Trust is especially important in long food supply chains, where producers and consumers are divided by numerous other FSC participants, such as packers, brokers, transporters, importers and retailers. A Researcher of food losses and waste asserts that "vertical integration partly solves the lack of trust that limits the potential benefits of collaboration [...]; but in a sense, this newly acquired trust [that comes from supply chain integration] is imposed upon [the FSC participants] rather than earned" [23]. One importer affirms that in the avocado industry, as in every food industry "trust takes long to win but can be easily lost" [1]. Yet, another importer goes beyond this statement by asserting that succeeding in reviving the trust between business partners after a problem is solved, may result in a strengthening of the relationship beyond that of a faultless relationship ${ }^{[3]}$. 
Most interviewees agree that often, the barrier to innovative collaboration is not a lack of communication between FSC participants, but rather a lack of effective communication able to penetrate the organizational culture in all the stages of the FSC until leading to change. Consequently, ineffective communication can lead to increased transaction costs, since more efforts have to be made in order to reach the desired outcome, and to bad planning, which in turn leads to postharvest losses. An importer states: "As importers, it is crucial to calculate the volume needed by our clients and to communicate this clearly to the producer, [...] for this, knowledge of the market is required to forecast the selling volumes in a determined week $^{[1]}$. A strategy often used to avoid coming short of product is to buy larger quantities than those demanded by the market. "We buy a little more than the expected demand in order to be sure of covering it all. Buying much more than needed will put a lot of pressure on the market, making prices increase, which will be at our disadvantage [4]".

In line with the findings of Soosay et al. (2008), interviewees acknowledge that a more detailed ${ }^{[1,2,7,22]}$, regular ${ }^{[1,3,6,9,16]}$ and honest $[4,5,7,18,24]$ communication would improve the accuracy of forecasted demands at all supply chain stages, thereby decreasing the risk of PHL. In this context, technological developments are being increasingly used to improve the detail and frequency of communication; however, their use is still mostly limited to the front-end of the supply chain. At the front-end of the FSC, retailers and suppliers often have electronic-based demand planning systems to synchronize order and deliveries. However, at the back-end of the FSC, communication technologies are implemented only to a certain degree by large companies and almost never by small and medium ones ${ }^{[6,19,22,27]}$. Small and medium producers, packers and exporters still share demand information through traditional channels, in both Colombia and Mexico. Some importers assert that to facilitate communication, they are increasingly establishing direct relations with producers ${ }^{[1,3,4,8]}$. However, others argue that although vertical integration is generally desired, when importers trade directly with small and medium producers, the differences in their organizational cultures and in the communication' technologies used may in some cases slow the development of the relationship ${ }^{[21,22]}$. In some cases, collaborative innovation gets hindered by old-fashioned ways of thinking and obstructive behaviors of FSC participants to innovation and collaborative developments. Interviewees expressed their frustration regarding the disinterest of some brokers in being a part of the solution. "They use arguments such as: 'why should I care if some product gets lost along the way if $i$ still can buy enough of it every day? -' or -'if we decrease the losses there would be an oversupply thereby bringing down the prices'- [22]. Most of the interviewees agree that such behaviors are old-fashioned and obstructive to innovation and collaborative developments. Table 3 presents an overview of the findings on the main drivers and barriers of innovative collaboration within the global avocado food supply chain.

The barriers and drivers of innovative collaboration along the FSCs show an interesting arrangement. Most of the barriers are related to cognitive and affective inefficiencies and the corporate inefficiencies, stemming from feelings and behaviors of FSC participants or from inappropriate corporate structures and managerial mechanisms. The drivers seem to relate more to tangible improvements in logistics, operations and efficiency. These findings could suggest that FSC participants perceive barriers to innovative collaboration from a wider perspective, as a broad set of institutional, governmental and behavioral conditions that negatively influence their functioning within the FSC. Drivers of innovative collaboration on the other hand, are perceived as a set of more specific and operational terms, which might have a motivational effect on FSC participants to work towards improvements, as these seem to represent individual benefits. In this context, reframing barriers in more pragmatic terms through which FSC participants perceive the influence of their individual actions on the FSC, could be a step forward towards overcoming them. The extent of experience that each country has in the avocado industry does not seem to be a direct determinant of the extent to which structural inefficiencies lead to postharvest losses. In this context, Colombia's shorter experience in producing avocado for export is sometimes portrayed as a major cause of the industry's weaknesses in its legal regulatory framework; Mexico's larger experience, however, is not reflected in a stronger regulatory framework. Mexico's larger experience and comparative advantages are not translated into more information exchange, better alignment of incentives, more effective partnerships or less inadequate uses of technology; neither is it reflected in less postharvest losses. This could be a consequence of the different extents of motivation of FSC participants of both countries to invest time, energy and money in improvements along the FSC. Mexican FSC participants have accumulated enough experience to improve productivity and to get rid of some structural inefficiencies, but still they seem to lack the motivation to do so, presumably due to the steady economic rewards of the industry as it is. Being by far the largest avocado producer in the world, the Mexican avocado industry seems to underestimate their competition and not encourage FSC participants enough to invest in further FSC improvements. At the same time, thanks to the industry's horizontal collaboration, the Colombian avocado industry has been able to build on the Mexican experience to fast track their improvement towards a more resource-efficient trade, with higher crop yields and less overseas' postharvest losses.

\subsection{Reducing postharvest losses through innovative collaboration}

Each of the components of innovative collaboration (i.e. information exchange, incentive alignment, effective partnerships and adequate use of technology) was found to contribute in different degrees to the reduction of postharvest losses, not only individually, but also through the interrelated dynamics that take place between them. Fig. 5 shows the refined conceptual model with the dynamics between the components of innovative collaboration.

As effective partnerships evolve with increased trust between FSC participants, the information exchange might become smoother and the fear to exchange sensitive information gradually smaller. Through the long-term interactions brought about by effective partnerships, FSC participants might be able to turn their cultural, organizational and economic differences into advantages by means of their complementary assets, thereby also aligning their incentives through a fairer distribution of costs and benefits. As incentives become more aligned between FSC participants they might be able to recognize the interconnectedness of their actions and align their objectives accordingly. In this context, suppliers for example, might be driven to improve their handling of the product at the back-end of the FSC by using technologies in more adequate ways, in order to avoid exporting a product that would present damage at the import stage, and would thereby result in postharvest losses. Likewise, effective partnerships can be identified as catalysts of technology' transfers between partners through which the recipient partner not only gains access to technology, but also to the knowledge and skills to use it adequately. Further research could be designed to study the dynamics between the components of innovative collaboration.

Consequently, effective partnerships were found to be the backbone of innovative collaboration, and the largest contributor to the reduction of postharvest losses within the framework of this study by functioning as catalysts of trust, communication, cooperation and innovation. An importer asserts: "Avocado is a difficult 
Table 3

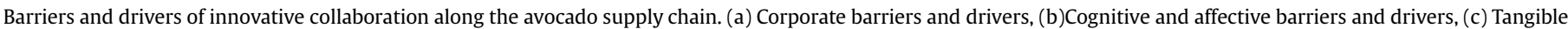
barriers and drivers.

a.

\section{Managerial/Regulatory}

- Some agreements reduce the availability of FSC participants to participate in other market opportunities

- Asymmetric extents of power

Economic/Financial

- Benefits occur at expenses of the autonomy of the less powerful participants in the relationship recurrent procedures that become habitual

Knowledge/Information

- Bad planning and incomplete communication

- Lack of effective, detailed, regular and honest communication

- Reduced transactional friction due to regular communication

b.

COGNITIVE AND AFFECTIVE BARRIERS

COGNITIVE AND AFFECTIVE DRIVERS

\section{Attitude}

- Reluctance to share sensitive information

- Resistance to change

- Opportunistic behavior

- Lack of interest and obstructive behaviors to innovation and collaborative developments

Perception

- Differences in working culture and opinions

- Increased risk-taking attitudes towards innovation due to risksharing practices

- Increased alignment of the organizational culture

- Increased expectations of positive results that strengthen commitment from participants

- Empowerment of the working staff as the exchange of ideas is encouraged and people get culturally integrated TANGIBLE BARRIERS TANGIBLE DRIVERS

\section{Logistics/Distribution}

- Industry-wide benefits are less appreciable than sectoral benefits

- Access to new logistics information

- Increased FSC efficiency and smoother logistics

- Increased supervision of processes from harvest to export, thereby increasing quality of product and risk of PHL

\section{Material/Sanitary}

- Access to new materials and technologies is compartmentalized and asymmetrical

- Increased access to new technologies

- Increased access to knowledge on best practices

product to be judged only by its external appearance; therefore, we rely on the trust that our suppliers live by the same quality standards and business values; partnerships are the catalyst of such trust" [3]. Three main types of partnerships have been identified along the avocado supply chain of both countries: (1) Partnerships between competitors; (2) partnerships between buyers and suppliers; and (3) research and development partnerships with national and international knowledge institutions. In some cases, however, partnerships also lead to learning races between FSC participants. This is in line with the findings of Cao and Zhang (2011) on supply chain collaboration in which FSC participants tend to engage in learning races to internalize others' resources and skills that could improve their individual performance. Such internalization of resources and skills was found to be asymmetric in nature, whereby small producers seem to obtain less economic and social benefits than other FSC participants. This is in line with Khanna et al. (1998)'s assertion that the benefits acquired by a partner from a partnership are likely to be proportional to the relative bargaining power of the partners involved. On the other hand, effective partnerships, R\&D partnerships in particular, were found to increase the symmetry in the reaping of benefits along the food supply chain. In this regard, according to Khanna et al. (1998), the incentives to engage in learning races (extended competitions to learn in which competition becomes progressively more important than collaboration) decrease as the reaping of benefits approaches a symmetric distribution along the FSC. Consequently, R\&D partnerships may also have the potential to compensate the need for learning races and contribute to an increase in collaborative relationships with more symmetric benefits' reaping. Fig. 6 shows a summary of the findings regarding the individual contributions by each component of innovative collaboration to the reduction of postharvest losses along FSC.

The results exemplify that, as Kaipia et al. (2013) and HLPE (2014) assert, reducing postharvest losses requires a focus on multiple parallel issues at the same time, and an approach that includes the behavioral, organizational, technological and contextual complexities to which global food supply chains are subject, at 


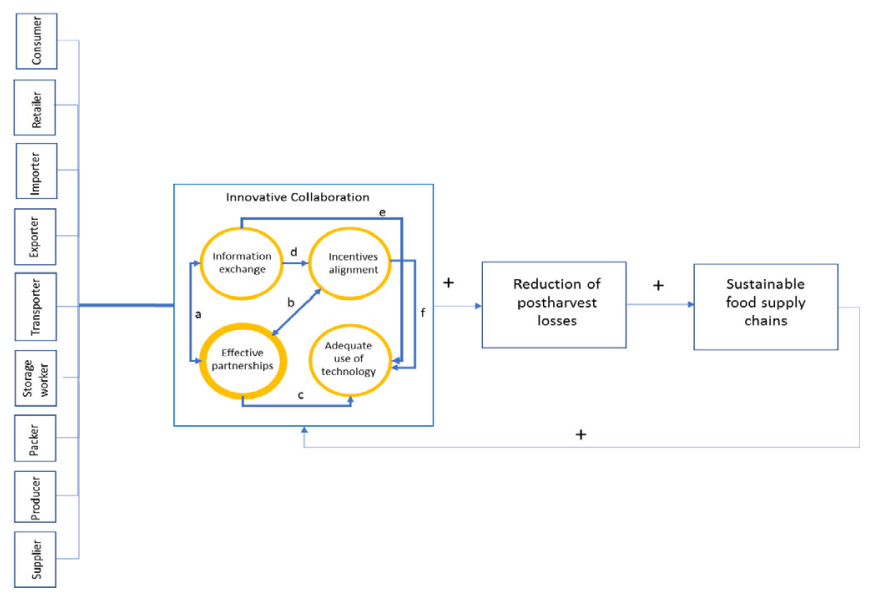

Fig. 5. The dynamics between the components of innovative collaboration contribute positively to the sustainability of FSC through the reduction of postharvest losses, thereby incentivizing further innovative collaboration among FSC participants. Effective partnerships were found to be the backbone of innovative collaboration contributing to the manifestation of all the other components ( $a, b$ and $c$ ). Information exchange has an influence on Incentives alignment (d) and on the adequate use of technology (e). Incentives alignment has an influence on the adequate use of tech$\operatorname{nology}(\mathrm{f})$.

individual and company, supply chain and institutional levels.

\section{Conclusion}

The main aim of this study was to understand how innovative collaboration influences the sustainability of global food supply chains through the reduction of postharvest losses.

Innovative collaboration seems to contribute positively to the environmental, economic and social dimensions of the FSC by for example, 1) avoiding unnecessary use of valuable resources and its entailed impact on the environment, 2 ) reducing the uncertainty of supply and demand, and stimulating a commercial vision among producers, thereby allowing them to increase profit, and 3) increasing the reliability of contracts between FSC participants, as well as improving the working conditions and learning options of small producers. Inter-personal interactions seem to be very important in paving the way towards more formal and long-term relationships. As relationships evolve, structural inefficiencies are gradually removed from the food supply chain due to positive behaviors becoming embedded in the organizational culture of FSC participants.

Engaging in effective partnerships was found to be the backbone of innovative collaboration, acting as a catalyst of positive behaviors that stimulate exchange of information, alignment of incentives and adequate uses of technology. Engaging in innovative collaboration, however, might not always succeed in addressing the structural inefficiencies that cause postharvest losses, since many other factors have influence on the FSC participants, the food supply chain and the food system. In this context, an enabling institutional environment that recognizes the importance of reducing postharvest losses to attain sustainable FSCs is essential. Furthermore, the findings show that without an integrated approach to postharvest losses, interventions could only result in a shift of the stage of the FSC in which postharvest losses take place. The case studies show that having more experience in the production and export of avocados does not equal having more expertise in avoiding the structural inefficiencies that lead to postharvest losses. We argue, however, that through horizontal collaboration the incumbents' experience provides support to entrants in accelerating their rate of improvement towards more sustainable food supply chains.

This paper has scientific contributions as well as limitations and

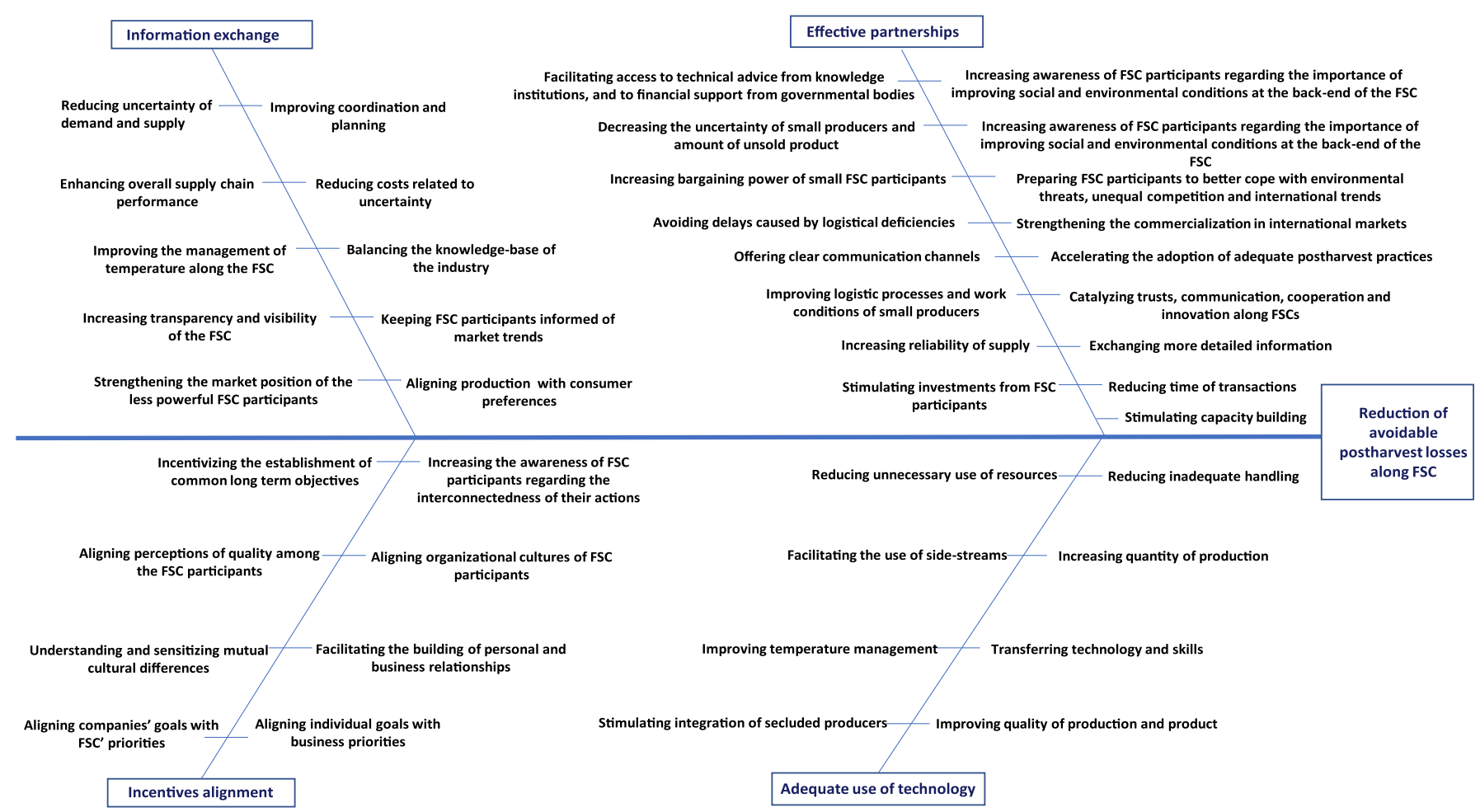

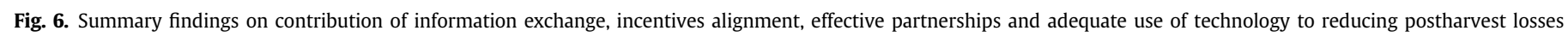
along FSC chains. 
implications for future research. Through the multiple case study approach, this research contributes to existing theoretical approaches on innovative collaboration and postharvest losses by offering a typology of structural inefficiencies in global food supply chains according to their underlying causes and mechanisms; herein, corporate inefficiencies, cognitive and affective inefficiencies and tangible inefficiencies were identified. This typology provides insight into the social drivers of postharvest losses by exploring the perceptions, attitudes and behaviors of FSC participants.

By categorizing the structural inefficiencies, a theoretical framework is created upon which further research can build on. In doing so, this research contributes to pointing out the direction of needed interventions to reduce PHL, thereby having also practical implications for managers of companies along FSCs, for policymakers and for practitioners in general, working towards the sustainability of global supply chains and towards the reduction of postharvest losses.

The data from the interviews contributes to deepen the understanding on the perceived barriers and drivers of FSC participants to use innovative collaboration to reduce postharvest losses within global agri-food supply chains. Regarding the limitations, the interviews sample might not represent the whole FSC proportionally, thereby limiting the generalizability of the findings. Most interviewees were producers/exporters and importers, especially since these are more easily accessible (through contact information in websites or mutual referral) than for example transporters, which generally don't limit their activities to a single product and are therefore less approachable within avocado networks. Future research could improve the external validity of these findings by using our interview protocol (appendix A) in case studies with a larger sample of interviewees or in case studies with different cultural, economic or organizational contexts.

\section{Acknowledgements}

We would like to thank Nina Waldhauer at The Postharvest Network for her valuable comments and insights on earlier drafts of this paper. Thanks also to the three reviewers for their time and valuable comments.

\section{APPENDIX A. Interview questions}

Towards sustainable food supply chains through innovative collaboration

Background

- Can you shortly introduce yourself? Work experience.

- How long have you been with this company/organization? In what capacities?

- What is your current position and what are your main responsibilities and objectives?

- What are your personal objectives in relation to reducing PHL?

- What are your personal objectives in relation to sustainability?

- What are your company/organization's objectives in relation to reducing PHL?

- What are your company/organization's objectives in relation to sustainability?

- How do you work daily towards meeting those objectives? What process do you follow and what inputs do you need?

Innovative collaboration within the food supply chain

Information Exchange
- How and with whom do you coordinate your activities? How and to whom do you communicate your results?

- How would you describe your relationship with other companies/organizations along the FSC? Do you have common objectives? How do you choose those objectives? How do you communicate and what kind of information is exchanged?

- Do you give or receive feedback after you sell/buy the product?

- With whom and how often do you communicate with other participants of the FSC?

- What communication channels do you use to communicate to other FSC participants

- What kind of knowledge do you exchange? (tacit or explicit knowledge)

Incentive's alignment

- Do you have shared responsibilities with other participants of the FSC regarding the quality of the final product?

- Do you have shared goals with other participants of the FSC regarding the final product?

- What is your main incentive to meet those goals? Is your performance evaluated in relationship to those goals? Is any kind of compensation linked to meeting those goals?

- Is there a regular assessment of the objectives to meet those goals?

- What is the reach of your responsibilities along the FSC of the product?

- Are there incentives for you to be involved in guaranteeing the quality of the product beyond your own gate?

- When trading with international companies, what kind of differences is more evident? (Very evident (2); More or less evident (1); Non-evident (0).

Economic Organizational Cultural

- To what extent do you consider important to align economic organizational and cultural incentives in order to enhance collaboration? Very important (2); More or less important (1); No important (0).

Economic Organizational Cultural

- What are the long-term objectives of your company/organization regarding the reduction of PHL?

- How does your company/organization define the quality of the product?

- Does your company/organization follow standardized policies and definitions to set goals and objectives?

Effective partnerships

- How do you solve problems regarding the quality of your product? Do you involve other participants of the FSC in the solution? 
- According to you, which participants along FSC play an important role in the reduction of PHL?

- What type of collaboration among FSC participants do you reckon? is it (formal, informal, short or long term)

- What do you consider to be important pre-requisites to engage in partnerships?

- Regarding the different parties that you have contact with regarding the reduction of PHL; how does the partnership function? How do you enhance each' others capabilities? Which procedures are in place to leverage the partnership?

- When you observe partnerships or collaborative arrangements between different participants of the FSC how would you describe them in terms of

- Knowledge spillovers

- Learning races between partners

- Difference in opinions regarding the intended results

- Flexibility and adaptability

- Trust between FSC participants

- Mutual respect

- Openness and transparency

- Designation of a qualified representative to manage the partnership

- Sense of ownership by FSC participants

- Sense of responsibility beyond own gate

Adequate use of technology

- How are shifts planned, task distributed and instructions given in the field?

- How do you make sure instructions are clearly understood and followed?
- Does your company/organization offer training to handlers?

- Does your company/organization use best handling practices?

- Does your company/organization use quality standards?

- Does your equipment fulfill the needs to produce the expected quality of the product?

- Do you think that the technology at disposition is fully harnessed?

- What do you think can be done better/differently regarding the use of the available technology?

- What do you think can be done better/differently in the innovation process of reducing PHL?

- What do you think are key factors to ensure the further success in reducing PHL?

- To what extent do you implement communication technologies in the trade of your product?

Closing questions

- Who do you think I should interview next?

- Would you be willing to be contacted later if clarification of this interview is needed?

- Would you be willing to provide the findings and analysis of this research with comments?

\section{APPENDIX B. List of interviewees}

\section{A. Semistructured interviews}

\begin{tabular}{|c|c|c|c|c|}
\hline Organization type & Country of operations & Job title of interviewee & $\begin{array}{l}\text { Reference } \\
\text { number }\end{array}$ & $\begin{array}{l}\text { Datum } \\
\text { interview }\end{array}$ \\
\hline Importer & $\begin{array}{l}\text { The Netherlands/ } \\
\text { Colombia }\end{array}$ & Product manager & 1 & $30-08-2016$ \\
\hline Importer & $\begin{array}{l}\text { The Netherlands/ } \\
\text { Mexico }\end{array}$ & Business Developer & 2 & 04-07-2016 \\
\hline Importer & The Netherlands & Team manager fruits & 3 & 05-08-2016 \\
\hline Importer & The Netherlands & Manager Sustainability & 4 & 09-08-2016 \\
\hline Importer & The Netherlands & Sales/Purchasing & 5 & 09-08-2016 \\
\hline Importer & The Netherlands & Continuous Improver & 6 & $11-08-2016$ \\
\hline Importer & The Netherlands & CSR Officer & 7 & $11-08-2016$ \\
\hline Importer & The Netherlands & Manager Sustainability and Marketing & 8 & $08-08-2016$ \\
\hline Producer/Exporter & Colombia & $\begin{array}{l}\text { Member of Corporation of Producers and Exporters of } \\
\text { Avocado }\end{array}$ & 9 & $19-08-2016$ \\
\hline Producer/Exporter & Colombia & Commercial manager & 10 & $15-08-2016$ \\
\hline Producer/Exporter & Colombia & Executive director & 11 & $18-08-2016$ \\
\hline Governmental organization & Colombia & Secretary of avocado chain & 12 & $17-08-2016$ \\
\hline Producer & Mexico & Sales/Purchasing & 13 & 20-09-2016 \\
\hline Producer/Exporter & Mexico & Sales consultant & 14 & $28-09-2016$ \\
\hline Producer/Exporter & Mexico & Commercial consultant & 15 & 21-09-2016 \\
\hline Governmental organization promoting international trade & Germany/Colombia & Investment specialist & 16 & 04-07-2016 \\
\hline Governmental organization promoting international trade & $\begin{array}{l}\text { The Netherlands/ } \\
\text { Mexico }\end{array}$ & Trade and Investment Commissioner & 17 & 08-07-2016 \\
\hline Growers Association & $\begin{array}{l}\text { The Netherlands/ } \\
\text { Mexico }\end{array}$ & Managing Director & 18 & $22-08-2016$ \\
\hline Growers Association & $\begin{array}{l}\text { The Netherlands/ } \\
\text { Mexico }\end{array}$ & Organizational Development manager & 19 & $22-08-2016$ \\
\hline $\begin{array}{l}\text { Fruit and Vegetables Sorting, Grading, Packing Technology } \\
\text { company }\end{array}$ & $\begin{array}{l}\text { The Netherlands/ } \\
\text { Mexico }\end{array}$ & Manager Customer Services & 20 & 24-08-2016 \\
\hline Knowledge Institution & The Netherlands & Expert in management studies & 21 & 03-08-2016 \\
\hline Knowledge Institution & The Netherlands & Project leader innovation projects & 22 & $08-07-2016$ \\
\hline Knowledge Institution & The Netherlands & Researcher of food losses and waste & 23 & 06-07-2016 \\
\hline Knowledge Institution & The Netherlands & Researcher & 24 & 05-07-2016 \\
\hline Knowledge Institution & The Netherlands & Researcher & 25 & $05-07-2016$ \\
\hline
\end{tabular}




\section{References}

Websites and Company documents Agricultural Marketing Resource Center, AgMRC, 2016. Avocados. Authors: Hayley Boriss, Henrich Brunke and Marcia Kreith, Agricultural Issues Center, University of California. Updated January 2016 by Christina Romero. AgMRC, California Polytechnic University, Pomona. Retrieved on 05 September 2016 from: http://www.agmrc.org/commoditiesproducts/fruits/avocados/.

Antunes, D., Miguel, G., Neves, A., 2007. Sustainable postharvest handling of horticultural products. WSEAS Trans. Environ. Dev. 3 (6), 111-116.

Arnold, M., 2017. Fostering sustainability by linking co-creation and relationship management concepts. J. Clean. Prod. 140 (2017), 179-18.

Arpaia, M.L., 2005. Avocado postharvest quality-an overview. In: New Zealand and Australia Avocado Grower's Conference. September 2005, vol. 5, pp. 20-22.

Barratt, M., 2004. Understanding the meaning of collaboration in the supply chain. Supply Chain Manag.: Int. J. 9 (1), 30-42.

BBC, 2016. Michoacán: cómo se convirtió un violento estado de México en el principal productor mundial de aguacate. Juan Paullier. BBC Mundo, Ciudad de México, 22 enero 2016. Retrieved on 17 June 2016 from: http://www.bbc.com/ mundo/noticias/2016/01/160121_mexico_aguacate_michoacan_oro_verde_jp.

Bill, M., Sivakumar, D., Thompson, A.K., Korsten, L., 2014. Avocado fruit quality management during the postharvest supply chain. Food Rev. Int. 30 (3), $169-202$.

Cao, M., Zhang, Q., 2011. Supply chain collaboration: impact on collaborative advantage and firm performance. J. Oper. Manag. 29 (3), 163-180.

CBI, 2015. CBI Product Factsheet. Fresh Avocados in Europe. Retrieved on 14 may 2016 from: https://www.cbi.eu/sites/default/files/product-factsheet-europefresh-avocados-2015.pdf.

Coronado, J.J.A., Bijman, J., Omta, O., Lansink, A.O., 2010. Relationship characteristics and performance in fresh produce supply chains: the case of the Mexican avocado industry. J. Chain Netw. Sci. 10 (1), 1-15.

Corpoica Colombia, 2010. In: Sandoval Aldana, A., Foreo Longas, F., Gracia Lozano, J. (Eds.), Postcosecha e innovacion del aguacate: Agroindustria rural innovadora. Centro de investigacion Natima, Espinal Tolima. Retrieved on 15 may 2016 from: http://bibliotecadigital.agronet.gov.co/bitstream/11348/4683/1/ POSTCOSECHADEAGUACATE.pdf.

Daly, H.E., Farley, J., 2011. Ecol. Econ.: Princ. and Appl, second ed. Island press.

Diario ABC de Michoacan, 2016. Aguacate michoacano, sin competencia nacional ni internacional: Benjamín Grayeb. May 31/2016. Retrieved on 12 August 2016 from: http://diarioabc.mx/noticias/?p=36743.

Durnell Cramton, C., Hinds, P., 2014. An embedded model of cultural adaptation in global teams. Organ. Sci. 25 (4), 1056-1081.

Faems, D., Van Looy, B., Debackere, K., 2005. Interorganizational collaboration and innovation: toward a portfolio approach. J. Prod. Innovat. Manag. 22 (3), 238-250.

FAO, 2004. AVOCADO: Post-Harvest Operation. Authors: Lidia Dorantes, PhD., Lidia Parada, MSc., Alicia Ortiz, PhD. Rome, Italy. Retrieved on 27 June 2016 from: http://www.fao.org/3/a-au996e.pdf.

FAO, 2011. Global Food Losses and Food Waste - Extent, Causes and Prevention. Rome Retrieved on 19 may 2016 from: http://www.fao.org/docrep/014/ mb060e/mb060e.pdf.

FAO, 2013. Food Wastage Footprint Impact on Natural Resources. Summary report. Retrieved on 13 may 2016 from: http://www.fao.org/docrep/018/i3347e/i3347e. pdf.

Garud, R., Jain, S., Kumaraswamy, A., 2002. Institutional entrepreneurship in the sponsorship of common technological standards: the case of Sun Microsystems and Java. Acad. Manag. J. 45, 196-214.

Gustavsson, J., Cederberg, C., Sonesson, U., Van Otterdijk, R., Meybeck, A., 2011. Global Food Losses and Food Waste. Food and Agriculture Organization of the United Nations (FAO), Rome.

HLPE, 2014. Food Losses and Waste in the Context of Sustainable Food Systems. A Report by the High Level Panel of Experts on Food Security and Nutrition of the Committee on World Food Security, Rome 2014.

Hodges, R.J., Buzby, J.C., Bennett, B., 2011. Postharvest losses and waste in developed and less developed countries: opportunities to improve resource use. J. Agric. Sci. 149 (S1), 37-45.

Hudnurkar, M., Jakhar, S., Rathod, U., 2014. Factors affecting collaboration in supply chain: a literature review. Proc. Soc. Behav. Sci. 133, 189-202.

Kaipia, R., Dukovska-Popovska, I., Loikkanen, L., 2013. Creating sustainable fresh food supply chains through waste reduction. Int. J. Phys. Distrib. Logist. Manag. 43 (3), 262-276.

Khanna, T., Gulati, R., Nohria, N., 1998. The dynamics of learning alliances: competition, cooperation, and relative scope. Strat. Manag. J. 19 (3), 193-210.
Kiaya, V., 2014. Post-harvest Losses and Strategies to Reduce Them. Tech. Pap. On Postharvest Losses. Action Contre la Faim (ACF).

Kummu, M., De Moel, H., Porkka, M., Siebert, S., Varis, O., Ward, P.J., 2012. Lost food, wasted resources: global food supply chain losses and their impacts on freshwater, cropland, and fertiliser use. Sci. Total Environ. 438, 477-489.

Lambert, D.M., Cooper, M.C., 2000. Issues in supply chain management. Ind. Market. Manag. 29 (1), 65-83.

Lambert, D.M., Cooper, M.C., Pagh, J.D., 1998. Supply chain management: implementation issues and research opportunities. Int. J. Logist. Manag. 9 (2), 1-20.

Lang, T., Barling, D., 2012. Food security and food sustainability: reformulating the debate. Geogr. J. 178 (4), 313-326.

Leach, M., Rockström, J., Raskin, P., Scoones, I.C., Stirling, A.C., Smith, A., Folke, C., 2012. Transforming innovation for sustainability. Ecol. Soc. 17 (2), 11.

Lee, T.W., 1999. Using Qualitative Methods in Organizational Research. Sage, Thousand Oaks, CA.

Lee, H.L., Whang, S., 2000. Information sharing in a supply chain. Int. J. Manuf. Tech. Manag. 1 (1), 79-93.

Lipinski, B., Hanson, C., Lomax, J., Kitinoja, L., Waite, R., Searchinger, T., 2013 Reducing Food Loss and Waste. World Resources Institute Working Paper, June. Installment of Creating a Sustainable Food Future. World Resources Institute, Washington, DC.

LKS, 2013. Plan de Negocios de Aguacate. Programa de Transformación Productiva November 2013. Retrieved in 15 may 2016 from: https://www.ptp.com.co/ documentos/PLAN\%20DE\%20NEGOCIO\%20AGUACATE\%20131211.pdf.

Lundqvist, J., de Fraiture, C., Molden, D., 2008. Saving water: from field to fork: curbing losses and Wastage in the Food Chain. SIWI Policy Brief.

Marshall, C., Rossman, G.B., 1995. Designing Qualitative Research, second ed. Sage, Thousand Oaks, CA.

Minagricultura, 2014. Estado Actual Y Perpectivas De La Cadena Del Aguacate En Aguacate En Colombia. Ministerio Ministerio de Agricultura y Desarrollo Rural. Author: FELIPE BAREÑO Retrieved on 17 may 2016 from: https://www.finagro. com.co/sites/default/files/node/basic-page/files/cadena_de_aguacate.pdf.

Pibernik, R., Zhang, Y., Kerschbaum, F., Schröpfer, A., 2011. Secure collaborative supply chain planning and inverse optimization-The JELS model. Eur. J. Oper. Res. 208 (1), 75-85.

Pippel, G., 2014. R\&D cooperation for non-technological innovations. Econ. Innovat. New Technol. 23 (7), 611-630.

Seuring, S., Müller, M., 2008. From a literature review to a conceptual framework for sustainable supply chain management. J. Clean. Prod. 16 (15), 1699-1710.

Simatupang, T.M., Sridharan, R., 2002. The collaborative supply chain. Int. J. Logist. Manag. 13 (1), 15-30.

Smith, B.G., 2008. Developing sustainable food supply chains. Philos. Trans.

The Guardian, 2016. Rising Avocado Prices Fueling Illegal Deforestation in Mexico, 10 august 2016. Retrieved on 17 October 2016 from: https://www.theguardian. com/lifeandstyle/2016/aug/10/avocado-illegal-deforestation-mexico-pineforests.

The World Bank, 2016a. Rural Population (\% of Total Population). Retrieved on 23 September 2016 from: http://data.worldbank.org/indicator/SP.RUR.TOTL.ZS? locations $=\mathrm{MX}$.

The World Bank, 2016b. Rural Population (\% of Total Population). Retrieved on 23 September 2016 from: http://data.worldbank.org/indicator/SP.RUR.TOTL.ZS? locations $=\mathrm{CO}$.

The World Bank, 2016c. World Development Indicators. Retrieved on 23 September 2016 from: http://databank.worldbank.org/data/reports.aspx? source=worlddevelopment-indicators.

Tielens, J., Candel, J.J.L., 2014. Reducing Food Wastage, Improving Food Security? Commissioned by: Food and Business Knowledge Platform.

Trienekens, J., Willems, S., 2007. Innovation and governance in international food supply chains: The cases of Ghanaian pineapples and South African grapes. Int. Food and Agribus. Manag. Rev. 10 (4), 42-63.

UN, 2016. Sustainable Development Knowledge Platform. A/RES/70/1-sustainable Consumption and Production. Retrieved on 17 June 2016 from: https:// sustainabledevelopment.un.org/index.php? page $=$ viewandtype $=2002$ andnr $=324$ andmenu $=35$.

Vermeulen, W.J.V., Witjes, S., 2016. On addressing the dual and embedded nature of business and the route towards corporate sustainability. J. Clean. Product. 112, 2822-2832.

WRI, 2016. Food Loss and Waste Accounting and Reporting Standard. Version 1.0 Retrieved on 07 August 2016 from: http://www.wri.org/sites/default/files/REP_ FLW_Standard.pdf.

Ziggers, G.W., Trienekens, J., 1999. Quality assurance in food and agribusiness supply chains: Developing successful partnerships. Int. J. Product. Econ. 60, $271-279$. 